\title{
Ultra stable iso-static bonded optical mount design for harsh environments
}

ICSO Ajaccio, 11. October 2012. Joep Pijnenburg, Martijn te Voert, Jan de Vreugd, Amir Vosteen,

Willem van Werkhoven, Jeroen Mekking, Bjorn Nijland.

TNO Optomechatronics, Delft, The Netherlands

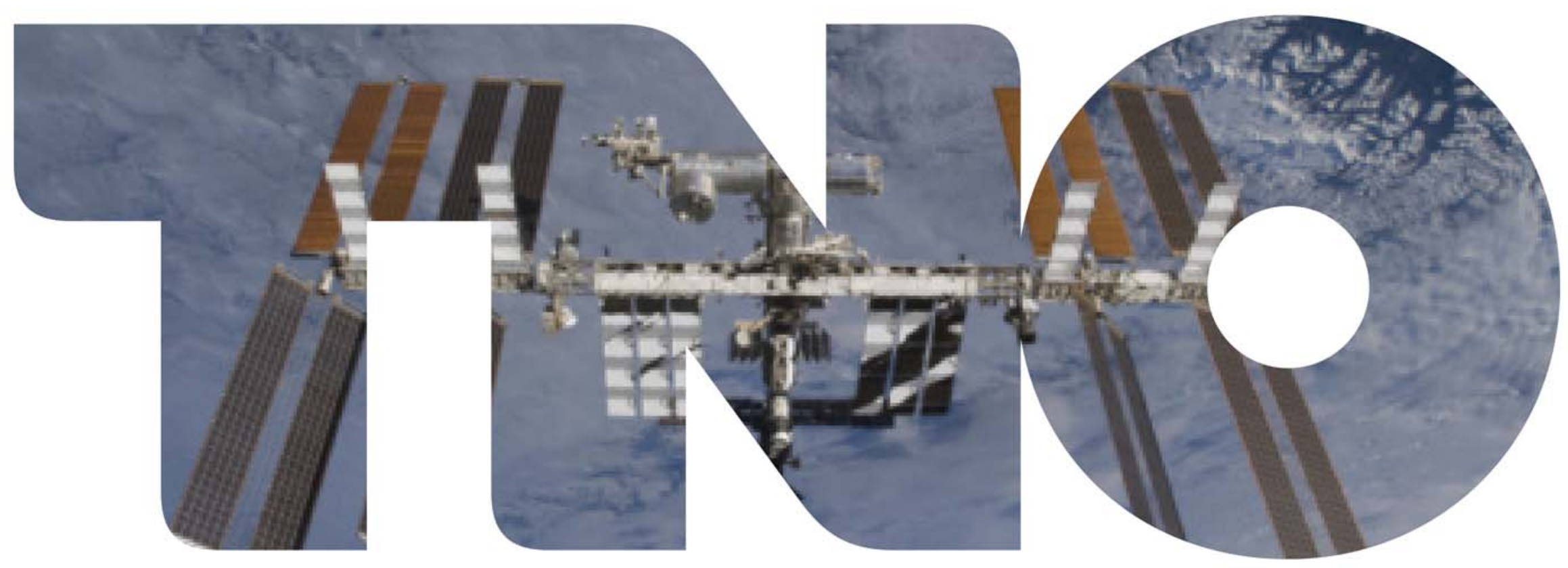




\section{Outline}

Introduction

> Concept of Iso-static bonded optical mount design

$>$ Design

Analysis

$>$ Testing

Application of the mounting concept

$>$ GAIA WFS

> TROPOMI

$>$ LISA PAAM

$>$ Euclid

$>$ Conclusions 


\section{Mounting optics; driving requirements}

Environmental Requirements

$>$ Transport loads:

$>$ Mechanical: Launch loads

> Thermal: Thermal survival loads

$>$ Cryogenic Operational temperatures

$>$ Vacuum, Zero gravity.

> Performance Requirements

$>$ Alignment

Stability (over life time, incl. launch)

$>$ Allowable Wave Front Error at (cryogenic) operational temperature.

$>$ Stress birefringence 


\section{Iso-static bonded mount concept}

Iso-static design principle:

'Leaf spring has high tensile + shear stiffness but low bending stiffness

Bond spot has high shear but low torsional stiffness

Each DOF of optical component is constrained once:

>Minimal and predictable forces and moments on optics.

No bending introduced due to asymmetry in bonding spots or mount.

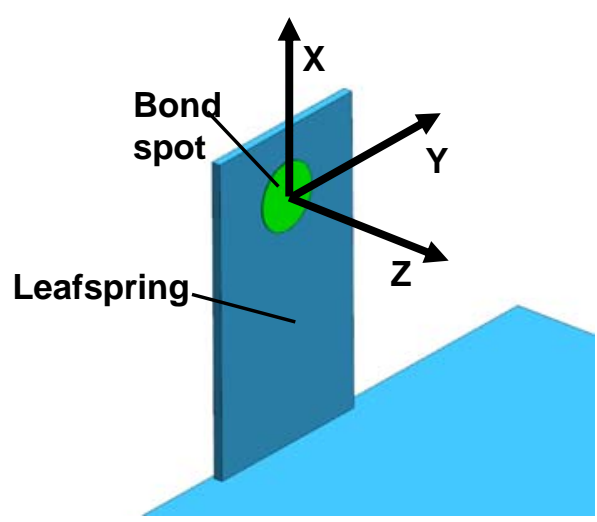




\section{Iso-static bonded mount concept: advantages}

> Defined and predictable Thermal Centre (TC) in all 3 translations.

$>$ Large CTE difference between optical and mount material can be coped with, careful selection and dimensioning of adhesive mandatory.

$>$ Mount design to a great extend independent of optical material.

$>$ No CTE matched "intermediate" material mandatory, this avoids large amplification during Random Vibrations of intermediate iso static interface.

$>$ Due to adhesive well damped "rigid" body modes of optics, $(\mathrm{Q}<25)$

$>$ Alignment of component can be performed with (standard) external tooling and "locked" with bonding spots.

$>$ CTE matching of materials works only as good as you knowledge of the material properties (5\%) and works only "perfect" at one homogeneous temperature! 


\section{Axial vs Tangential leaf spring orientation}

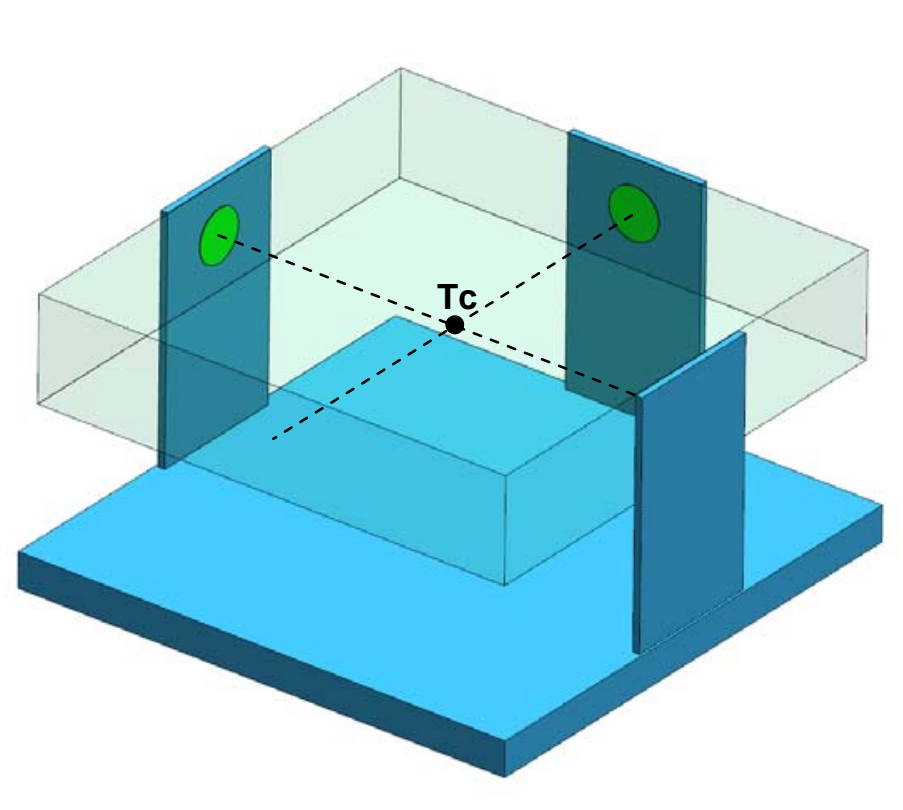

$>$ Residual leaf spring bending moment out of plane of optical component: Careful dimensioning of leaf springs mandatory for low WFE.

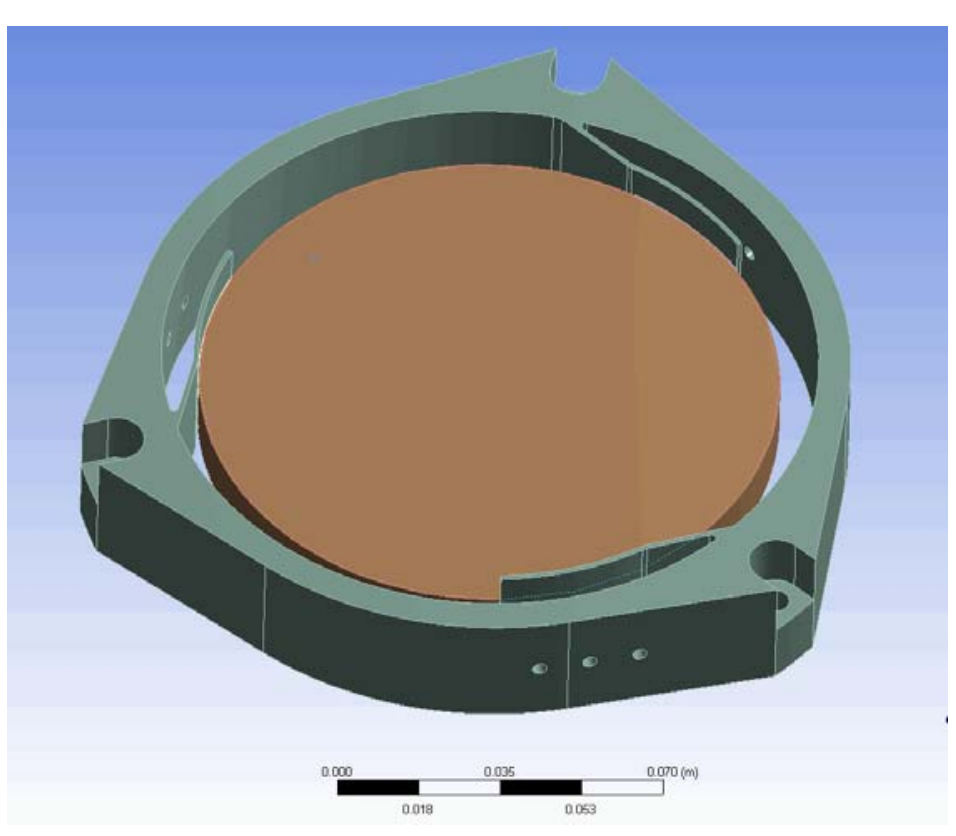

$>$ Small rotation of component due to cool down

$>$ Different envelopes

$>$ Residual bending in plane of the component. 


\section{Analysis}

> Dimensioning done with analytical models.

> Adhesive selection based on Visco Plastic/Elastic Adhesive Properties in combination with (Thermal) environment.

$>$ If needed: optimization done with FE analysis:

$>$ Random Vibration analyses.

$>$ Shock analyses.

> WFE and stability prediction under operational conditions.

> Stresses prediction in optics and mount, Visco Plastic/Elastic material properties have been measured and implemented in in house developed FE Analyses tools. For details see SPIE 8450-156 Jan de Vreugd et. al. 


\section{Environmental testing}

$>$ A typical environmental test campaign for an optical mount consists of:

$>$ Random vibration testing

> Shock testing

$>$ Thermal cycling in Vacuum or Dry N2
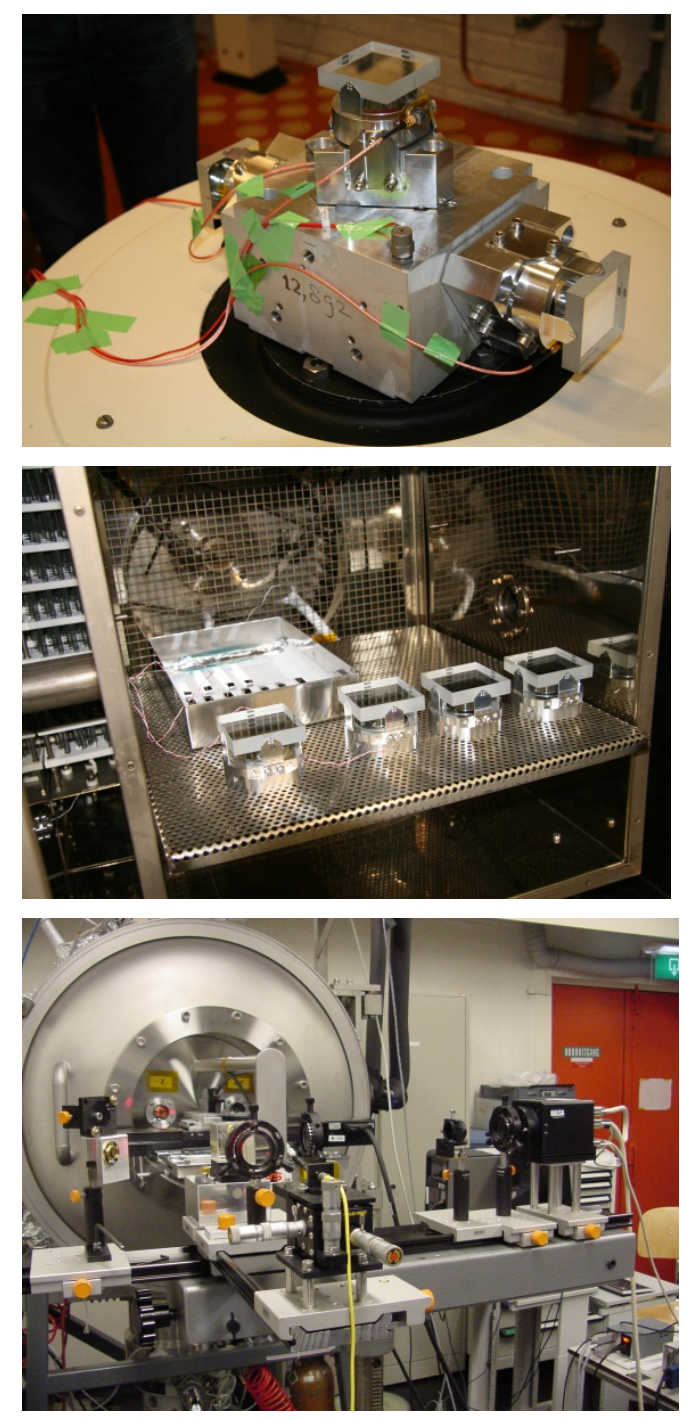


\section{Stability verification by test}

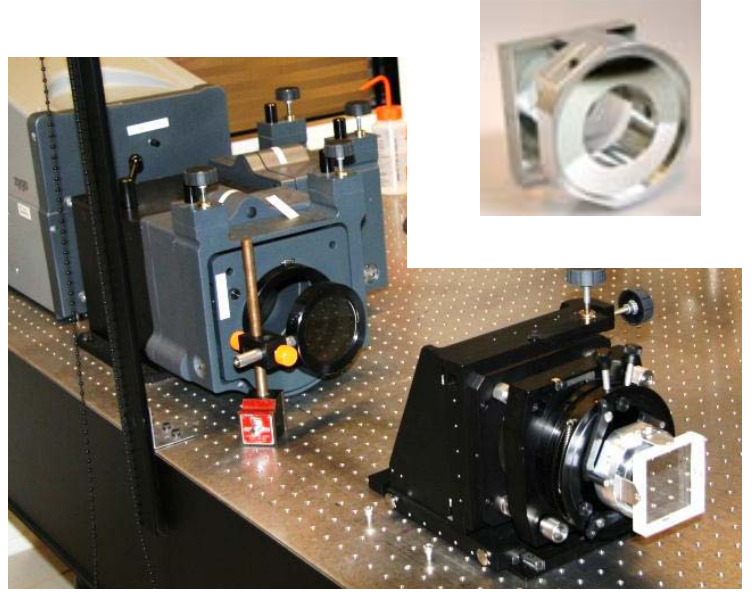

> Zygo Verify interferometer for stability measurement

> Tip/tilt stability

$>$ WFE

> Relative measurement between

$>$ Diamond turned reference on mount

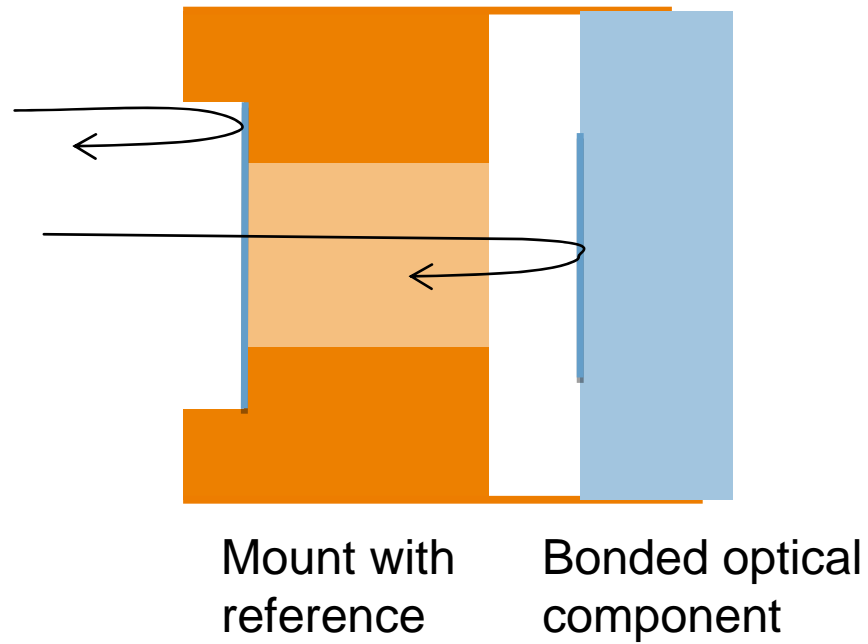

> Reflective coating on optics

$>0.5 \mu \mathrm{rad}$ accuracy achievable 


\section{WFE verification by testing}

$>$ WFE measurement under operational conditions:

$>$ vacuum

$>$ Cryogenic

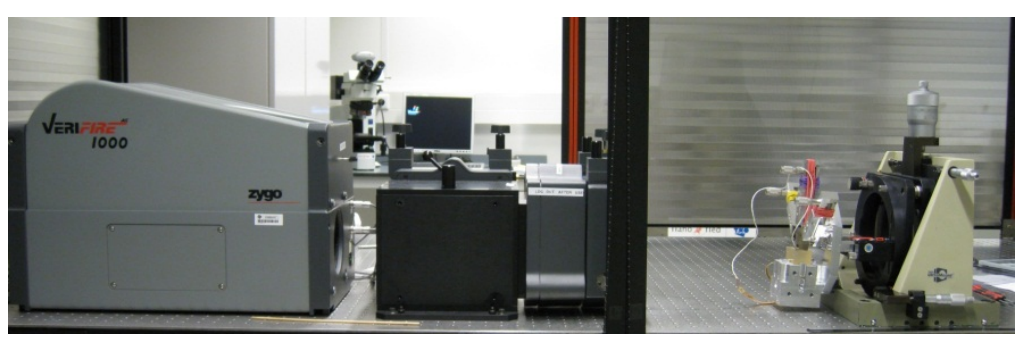

> Down to $90 \mathrm{~K}$ at TNO test facility and aperture of $100 \mathrm{~mm}$.

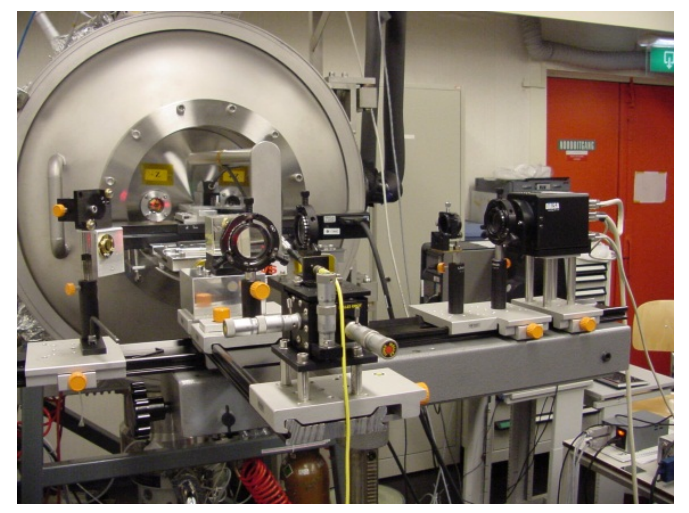

$>$ Down to $4 \mathrm{~K}$ and aperture of 150 $\mathrm{mm}$ at NOVA Astron, Dwingelo, The Netherlands.

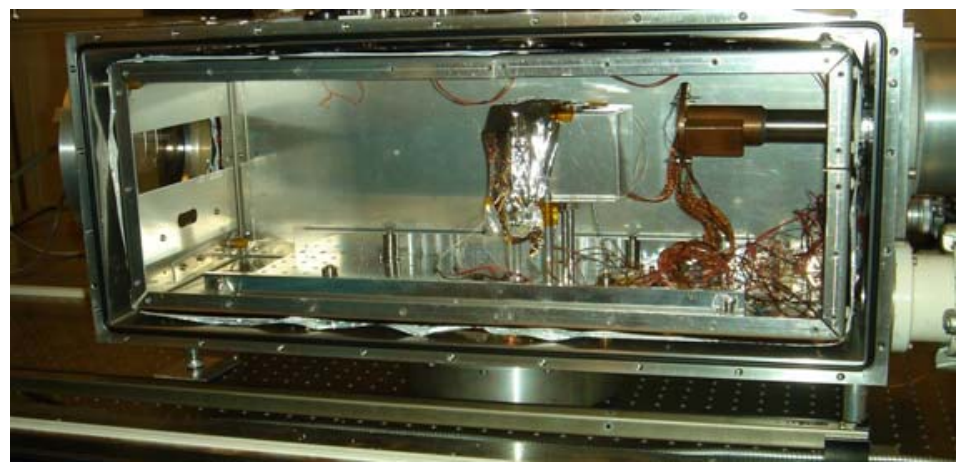




\section{Application: GAIA WFS mounts}

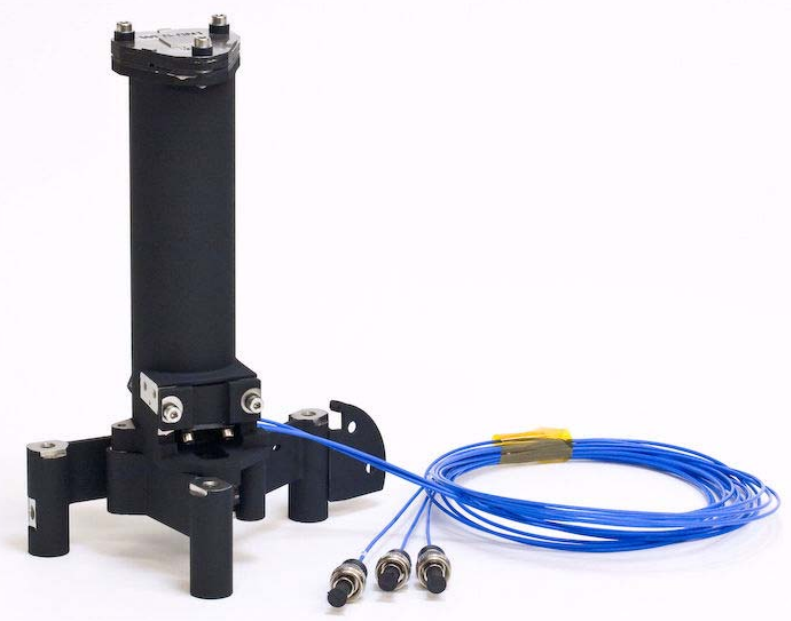

> Various concepts breadboarded

> Leafspring design met all requirements:

$>$ WFE $<3 \mathrm{~nm}$ rms

> Tip/tilt stability $<50 \mu \mathrm{rad}$

> Verification testing:

> Random vibration, 30 grms

> Thermal cycling, $100 \mathrm{~K}$ to $350 \mathrm{~K}$

$>$ Stability $<9$ urad

$>$ WFE at cryogenic vacuum

Iso-static

Mechanical

Continuous conditions < $24 \mathrm{~nm} \mathrm{PV}$ 


\section{Application: TROPOMI mounts}

- Fused silica components bonded to an aluminium mount

- Bond spot optimized to overcome local CTE difference (23 ppm vs. 0.5 ppm)

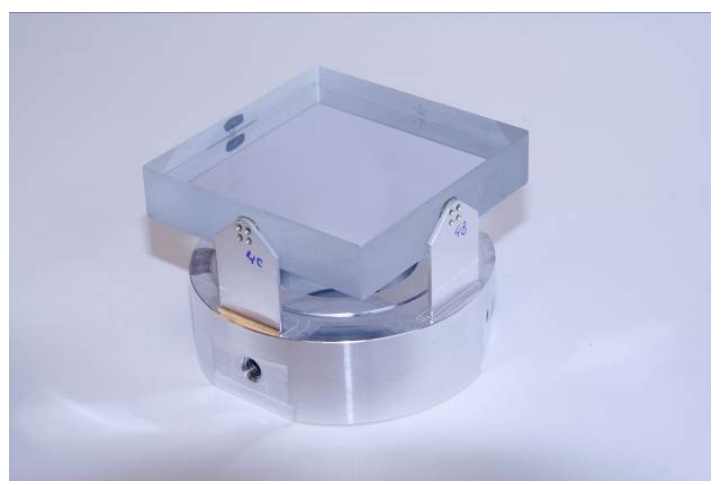

Breadboard 1: $70 \times 70 \mathrm{~mm}, 0.2 \mathrm{~kg}$

- Verification by test of breadboard 1:

- Random vibration $14.4 \mathrm{grms}$

- Thermal cycling $-50{ }^{\circ} \mathrm{C}$ and $+45^{\circ} \mathrm{C}$

- No mechanical degradation

- Tip Tilt Stability below 5 urad

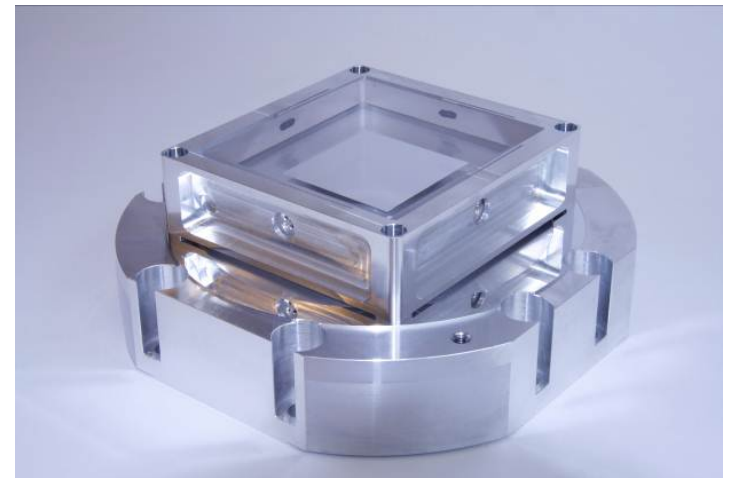




\section{Application: LISA PAAM}

> Scan mechanism with picometer stability over hours.

$>$ Bonded Iso static mirror mount implemented.

$>$ Critical requirements.

> Pointing stability over lifetime $<4$ micro radians, (incl Launch)

> Piston stability in picometer range during measurement of hours

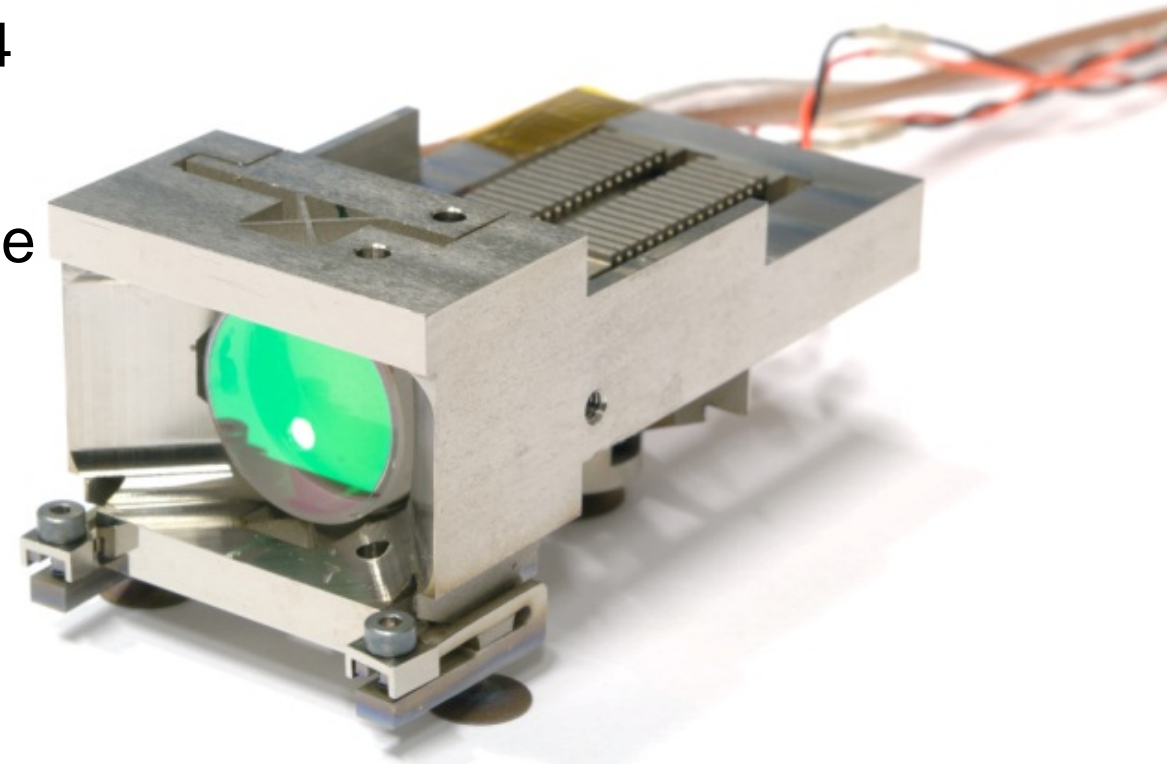




\section{PAA Mechanism Piston stability measurement}

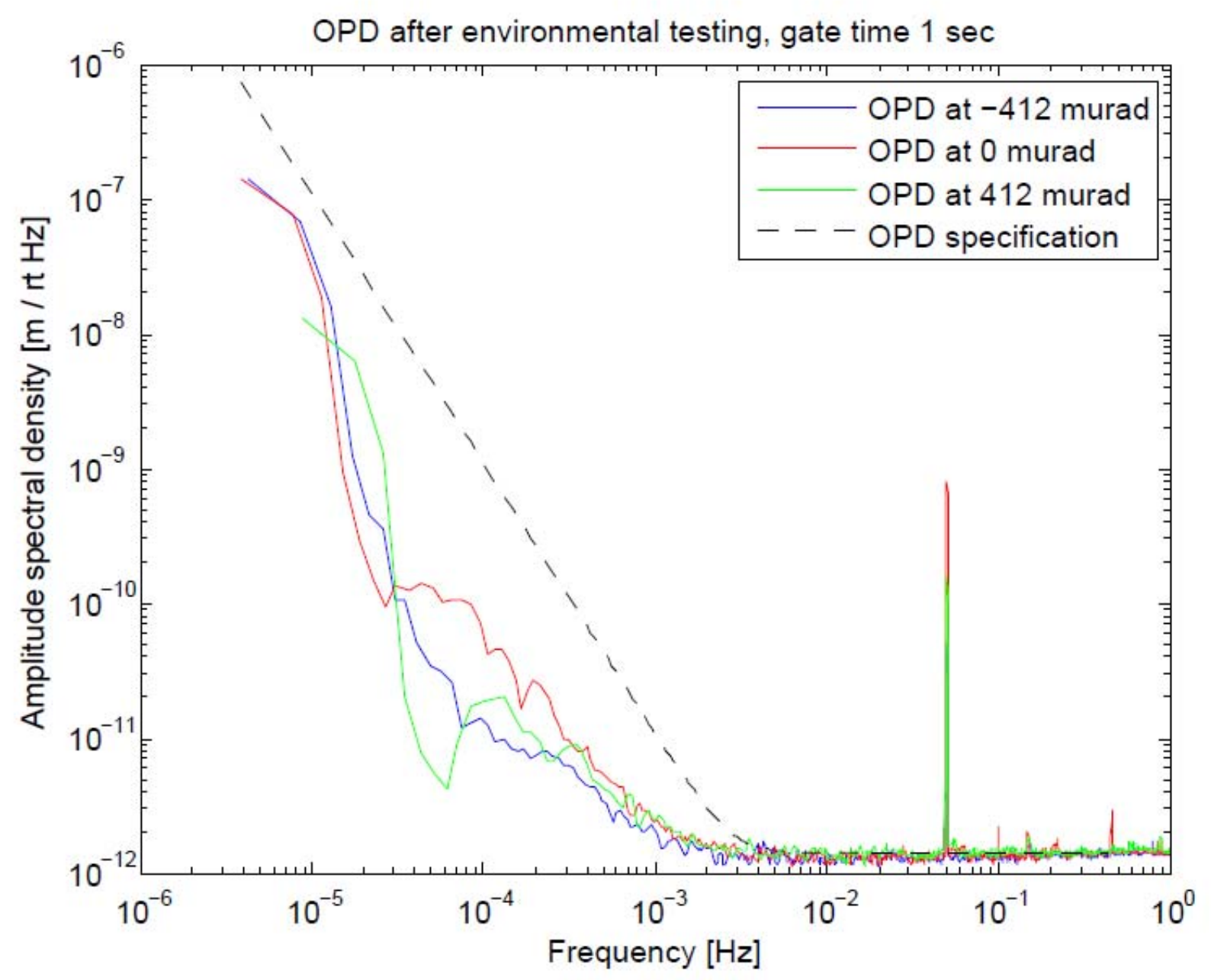

Measurement performed by Albert Einstein Institute, Hannover. 


\section{Application: Euclid Cryogenic mount for large optics}

Driving Requirements:

> $0.5 \mathrm{~kg} \mathrm{CaF2}$ blanks $\mathrm{D}=$ $125 \mathrm{~mm} \mathrm{t}=10 \mathrm{~mm}$

$>60 \mathrm{~g}$ quasi static launch loads

> $120 \mathrm{~K}$ to $313 \mathrm{~K}$ Thermal survival range

> WFE $<68 \mathrm{~nm}$ P-V at $140 \mathrm{~K}$

$>$ Angular stability over life time (including launch and cool down to $140 \mathrm{~K}$ ) goal: $<25$ micro radian.

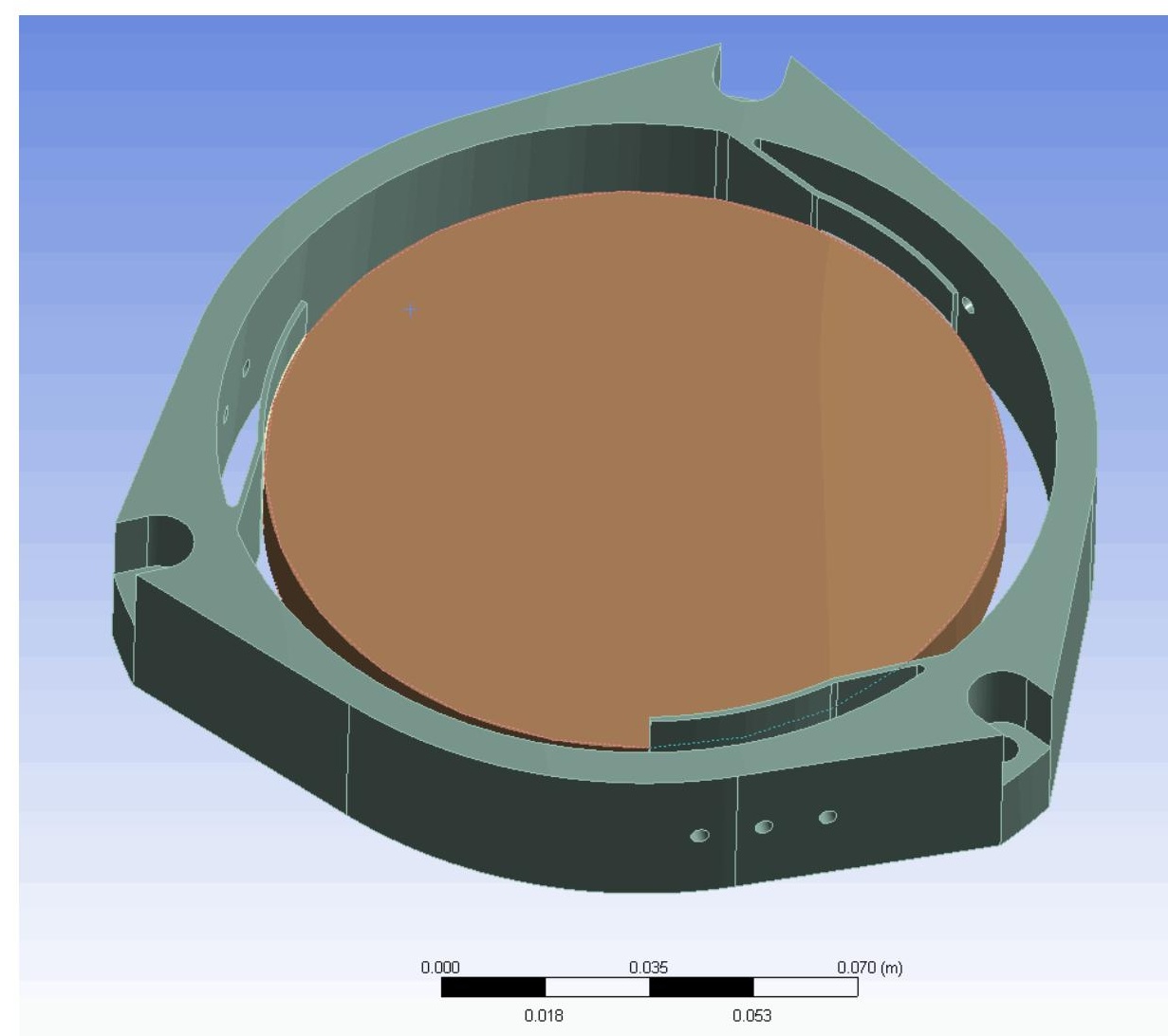




\section{Application: Euclid Cryogenic mount for large optics}

Bonded tangential leaf spring mount.

$>$ Optimized adhesive and leaf spring dimensions and properties for:

$>$ High stiffness and stability (First mode $>550 \mathrm{~Hz}$ )

$>$ Low stresses in Glass due to launch and cool down (< $4 \mathrm{MPa}$ )

$>$ Low WFE

$>$ Design ready for manufacturing and testing.

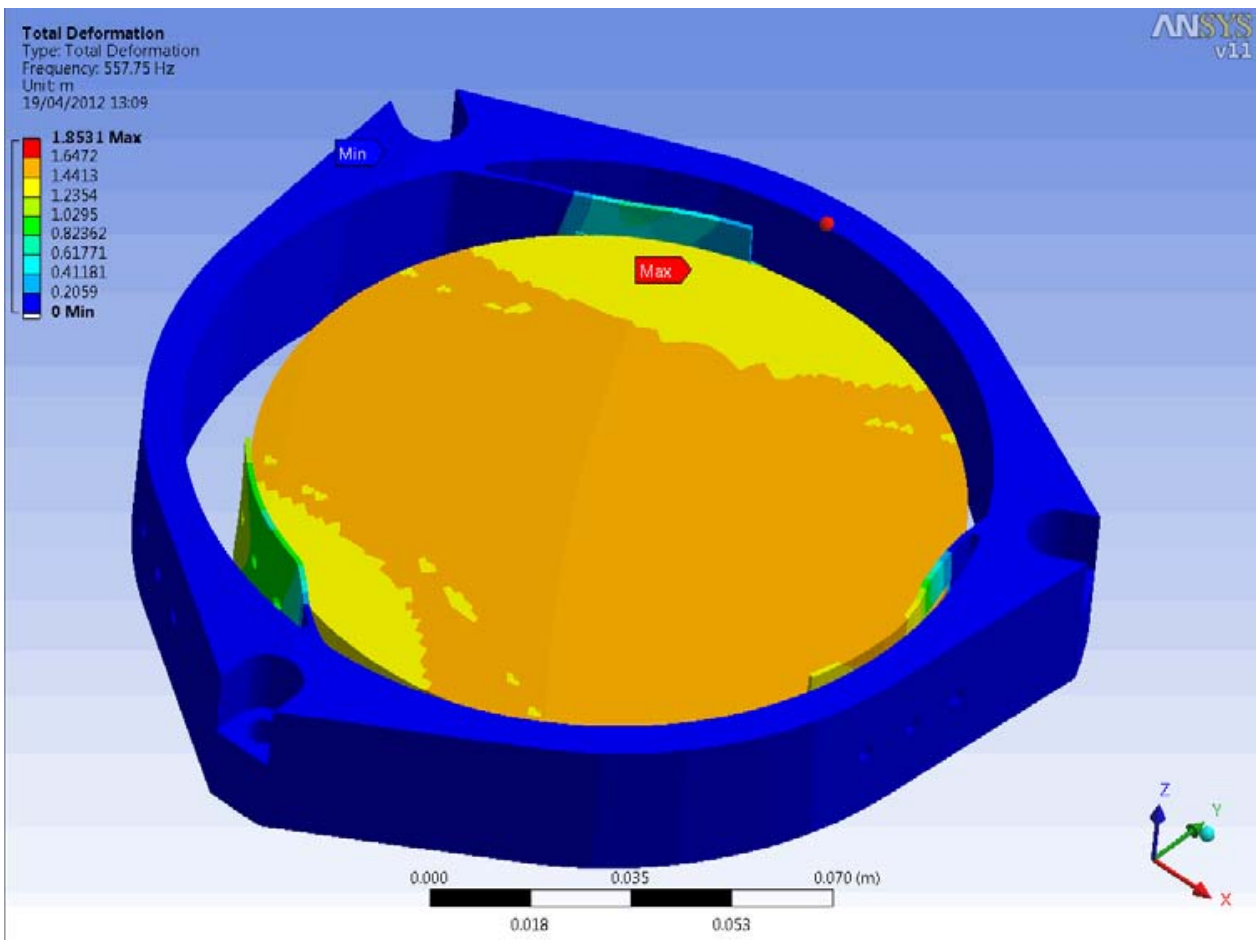




\section{Application: Euclid Cryogenic mount for large optics}

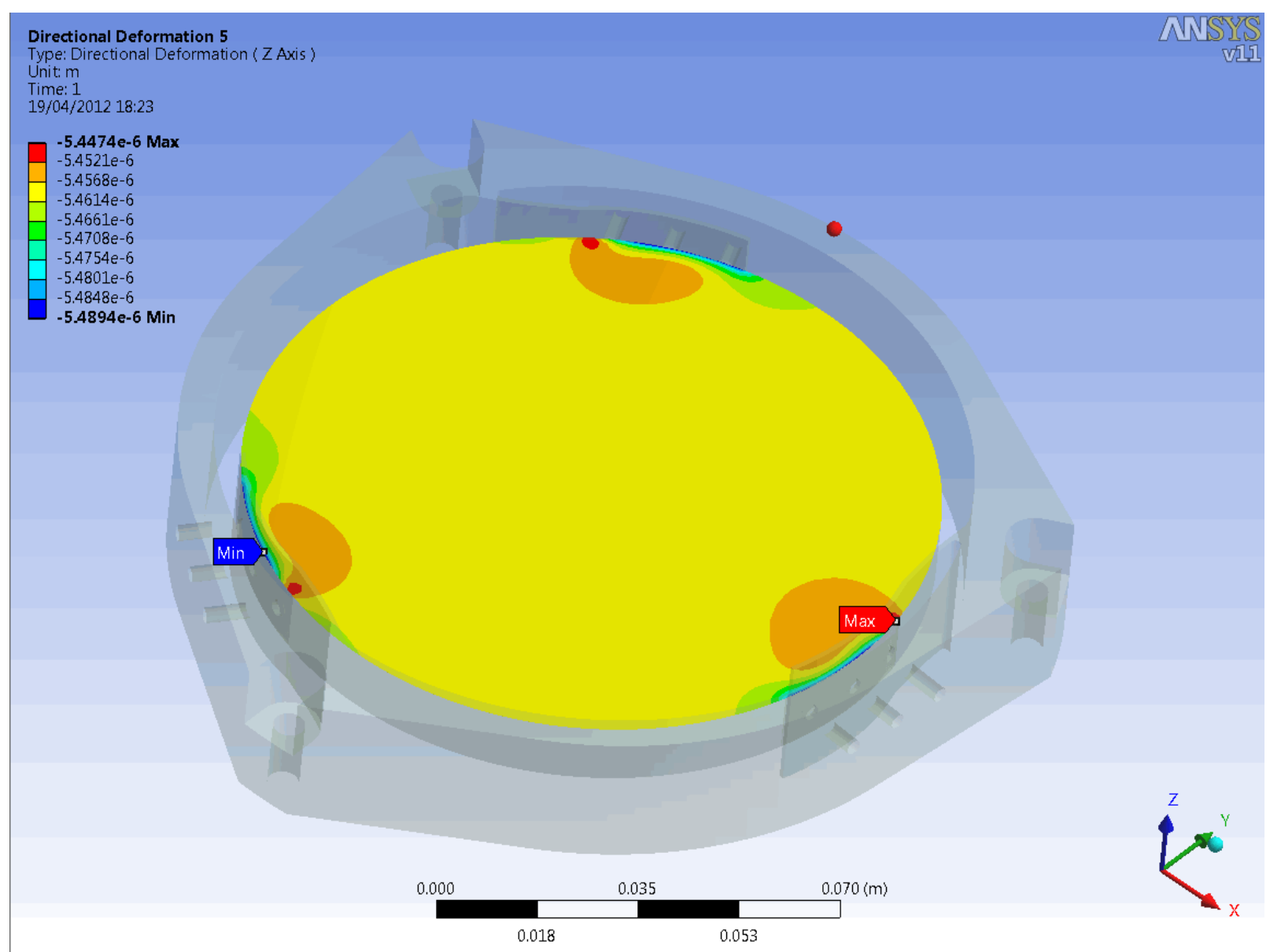

Predicted Surface deformation $<42 \mathrm{~nm}$ P-V 


\section{Conclusions}

$>$ The iso static bonded mount concept can be implemented for various application, main advantages:

$>$ High stability up to 1 micro radian over life time including launch.

$>$ Low and predictable WFE.

$>$ Simple and cost effective design

$>$ Alignable up to 1 micro radian with external tooling

$>$ Supported by TNO developed analyses and experimental verification methods.

$>$ Design, Analyses and Test infrastructure, for WFE measurements at cryogenic temperatures in cooperation with NOVA Astron, Dwingelo, The Netherlands.

> TNO can in house characterise your adhesives and implement the material models in your FE tools. 


\section{Acknowledgements}

TNO has been able to develop build and test thanks to the work of and cooperation with;

$>$ ESA, NSO

Astrium EADS

$>$ Dutch Space, Leiden, The Netherlands

> Albert Einstein Institute, Hannover, Germany

$>$ NOVA Astron, Dwingelo, The Netherlands

TNO likes to thank all of them for their contribution! 


\title{
Thanks for your attention!
}

\author{
Questions?
}

